\title{
Saving a Million Species
}

EXTINCTION RISK FROM CLIMATE CHANGE

Edited by Lee Hannah

\section{Oislandpress}

Washington | Covelo | London 


\title{
Copyright (C) 2012 Island Press
}

All rights reserved under International and Pan-American Copyright Conventions. No part of this book may be reproduced in any form or by any means without permission in writing from the publisher: Island Press, 1718 Connecticut Avenue NW, Suite 300, Washington, DC 20009

Island Press is a trademark of The Center for Resource Economics.

\section{Library of Congress Cataloging-in-Publication Data}

Saving a million species : extinction risk from climate change / edited by Lee Hannah.

$$
\text { p. } \mathrm{cm} \text {. }
$$

ISBN-13: 978-1-59726-569-0 (cloth)

ISBN-10: 1-59726-569-1 (cloth)

ISBN-13: 978-1-59726-570-6 (paper)

ISBN-10: 1-59726-570-5 (paper)

1. Climatic changes. 2. Global warming. 3. Extinction (Biology)-Environmental aspects. I. Hannah, Lee Jay.

QC902.9.S28 2011

$551.6-\mathrm{dc} 23$

2011040327

Printed on recycled, acid-free paper

\author{
(4) \\ Manufactured in the United States of America \\ 10987654321
}

Keywords: Island Press, climate change, extinction, extinction risk, biodiversity, freshwater, marine, biology, coral bleaching, species area relationship, million species, conservation 




\section{O N T E N T S}

Foreword

THOMAS E. LOVEJOY

PART I. INTRODUCTION

Chapter 1 Are a Million Species at Risk?

Lee Hannah

Chapter 2 First Estimates of Extinction Risk from Climate Change

Chris D. Thomas

Chapter 3 Climate Change, Extinction Risk, and Public Policy Jonathan Mawdsley, Guy Midgley, and Lee Hannah

PART II. REFINING FIRST ESTIMATES

Chapter 4 Refining Risk Estimates Using Models Alison Cameron

Chapter 5 The Use and Misuse of Species-Area Relationships in Predicting Climate-Driven Extinction John Harte and Justin Kitzes

PART III. CURRENT EXTINCTIONS

Chapter 6 First Extinctions on Land Sarah K. McMenamin and Lee Hannah

Chapter 7 Global Warming and Widespread Coral Mortality: Evidence of First Coral Reef Extinctions Peter W. Glynn

Chapter 8 Extinction Risk at High Latitudes 
Peter J. Mayhew

Chapter 10 Terrestrial Ecosystem Response to Climate Change during the Paleogene

William C. Clyde and Rebecca LeCain

Chapter 11 Quaternary Extinctions and Their Link to

Climate Change

Barry W. Brook and Anthony D. Barnosky

Chapter 12 Quaternary Tropical Plant Extinction:

A Paleoecological Perspective from the Neotropics

Mark B. Bush and Nicole A. S. Mosblech

PART V. PREDICTING FUTURE EXTINCTIONS

Chapter 13 Every Species Is an Insect (or Nearly So): On Insects, Climate Change, Extinction, and the

Biological Unknown

Robert R. Dunn and Matthew C. Fitzpatrick

Chapter 14 Extinction Risk from Climate Change in

Tropical Forests

Yadvinder Malbi

Chapter 15 Coral Reefs, Climate Change, and Mass Extinction

Ove Hoegh-Guldberg

Chapter 16 Extinction Risk in a Changing Ocean

Benjamin S. Halpern and Carrie V. Kappel

Chapter 17 Climate Change and Freshwater Fauna

Extinction Risk

N. LeRoy Poff, Julian D. Olden, and David L. Strayer

Chapter 18 Climate Change Impacts on Species Interactions:

Assessing the Threat of Cascading Extinctions

Lesley Hughes

PART VI. CONSERVATION IMPLICATIONS

Chapter 19 Strategies for Reducing Extinction Risk under a Changing Climate 
Chapter 20 Saving a Million Species

Lee Hannah

Contributors

395

Index

407 

It is decades since the "eureka moment", as Stephen Schneider dubbed the time I asked him, "What does what you do (climate change) have to do with what I do (biodiversity)?" Since then, relevant science has gone from projections based on paleontological data, through Chris Thomas and colleagues' 2004 forward projection of the extinction consequences of doubling preindustrial carbon dioxide, and beyond. Today there seems to be a rush of new observations of climate-induced biological change almost daily.

It is within this trajectory of growing understanding that the editors and authors have assembled this important volume. It makes a critical contribution. Even though the initial increments of change are mostly (but not entirely) small, they at least partly unveil what can lie beyond. At early stages it is often very difficult to differentiate between linear and exponential change, and it can be easy to ignore the profoundly important. In addition, the inherently (and necessarily) conservative approach of the Intergovernmental Panel on Climate Change (IPCC) has reinforced that to the point of consistently underestimating the extent of the biodiversity-climate change problem.

Impacts on the living planet are already pulling away from that phase and demonstrating the change to be exponential. There is already abrupt change at the ecosystem level. Coral reefs are a clear example as they experience "bleaching" events in which diversity, productivity, and human benefit crash. Unknown prior to 1984, they now are commonplace and chronic. We are seeing similar threshold change in the coniferous forests of western North America: milder winters and longer summers have tipped the balance in favor of native bark beetles such that in many places 70 percent of the trees are dead. These two changes are tantamount to ecosystem failure with major and as yet only superficially understood consequences for constituent biodiversity.

There is an imperative need to move beyond the initial phase of climate change science in which physical science has dominated. Biology must become central to climate change science and policy 
formulation. The planet does not work just as a physical system, but rather as a linked biological and physical system; that reality needs to become fundamental to the way we pursue the science and derive policy recommendations.

It is important to remember that the effects we are currently seeing are caused by global warming of a bit more than 0.75 degree Celsius. The inconclusive policy debates in Cancún and previously in Copenhagen were primarily around reining in greenhouse gas emissions to stop climate change before or at 2.0 degrees Celsius. It doesn't take a lot of thinking to realize that 2 degrees Celsius is too much for ecosystems and that we should choose a less disruptive goal of, say, 1.5 degrees Celsius.

The awful reality is that if we decide to stop at 2 degrees Celsius, global emissions have to peak in 2016. Many would say there is no hope of even stopping at 2 degrees Celsius. Also, many of the models project much greater increases in greenhouse gases (double and triple preindustrial levels) and consequent global temperature. The folly of allowing this from a biological point of view is well laid out in this volume.

Just a single example is "Amazon dieback", in which the forest would die back and be replaced by savannah vegetation in the south and east-southeast of Amazonia. First projected to occur at 2.5 degrees Celsius by the Hadley Center's general climate model, subsequent refinement lowered the threshold to 2 degrees Celsius (the very target discussed by the negotiators). This would represent a staggering loss of biological diversity, serious impacts on the indigenous and other peoples living in that part of the Amazon, and a huge release of more carbon to the atmosphere. Ominously, there was probably a preview in 2005, when the Amazon had the greatest drought in recorded history. This was repeated with an even more intense drought in 2010.

Further, because the high wall of the Andes stops the westward movement of moisture, it both generates the rainfall that largely creates the Amazon river system and sends airborne moisture to the north and south of the Amazon. Termed "rivers in the sky" the moisture provides essential rainfall to agro-industry south of the Amazon and further-at least as far as northern Argentina. What is clear is that the effects approach a continental scale.

The picture is further complicated by other impacts on the hydrological system of the Amazon, namely those of deforestation and fire. The World Bank invested a million dollars in a modeling study look- 
ing at the combined effects of deforestation, fire, and climate change. The disturbing result was the suggestion of a tipping point to dieback at around 20 percent deforestation, with the current extent being about 18 percent. In this case there is an obvious policy response, namely to aggressively reforest in the south and east to build back a margin of safety.

On top of these issues is the acidification of the oceans as a consequence of the higher atmospheric concentrations of carbon dioxide. Our understanding of the implications for marine species and ecosystems is rudimentary at best, as laid out in the oceans chapter. When it comes to "solutions", those that address temperature must be viewed mostly skeptically not only because they address a symptom and not the cause, but also because they ignore the effects of acidification of the marine two-thirds of the planet.

This volume essentially makes the case that the planet is a biophysical system and that the biological elements make it very important to limit climate change and further buildup of greenhouse gases. It also takes us beyond that to thinking about ways to use the planetary biophysical system to pull carbon dioxide out of the atmosphere. That has happened twice in the history of life on Earth-the first with life and green plants emerging onto land, and the second with the advent of modern flowering plants. It shows that biology has very great power. The problem from a practical (and very anthropocentric) point of view is that we don't have tens of millions of years to achieve this a third time.

It is rarely expressed this way, but roughly half of the excess carbon dioxide in the atmosphere actually comes from the destruction and degradation of ecosystems over the past three centuries. That means we can choose to manage our planet as a biophysical system and pull significant amounts of carbon dioxide out of the atmosphere by ecosystem restoration on a planetary scale. In one sense, it is tantamount to joining forces with, rather than working counter to, Gaia (in a nonmystical sense). This is not the place for details of a debate over how much carbon dioxide could be sequestered in such fashion and what that might mean in terms of land use decisions. Suffice it to say it seems that roughly 50 parts per million of carbon dioxide could be pulled out of the atmosphere in a half-century period without impinging on land necessary for agricultural production to support 9 billion people.

This is not the place for further elaboration-however essential it might be-of additional nonbiological solutions for lowering 
atmospheric carbon dioxide. What the editors and authors who have created this volume have achieved is to make an impregnable case for the sensitivity of the biology of our planet to the changes we are creating in the atmosphere. And by implication, they lay the basis for engaging the biology of the planet in a grand solution. Were we to recognize and seize on this, it would be a magnificent new chapter in organic evolution, one in which consciousness (itself a consequence of evolution) rises above its immediate and petty concerns to create a better future for humans and all life on Earth.

This, of necessity, would require a very different worldviewnamely, one in which the limits of the global biophysical system are embraced, but simultaneously, the system's power is engaged to achieve a sustainable outcome for humanity and life on Earth. Interestingly, studies of the 2 billion poor of the planet indicate they depend very directly and to great degree (38-89 percent) on goods and services from biodiversity and ecosystems. A global commitment to regreen the "emerald planet" would recognize that a similar dependence and respect is important for all humanity.

Thomas E. Lovejoy 